\title{
Article \\ N-Alkylmorpholines: Potent Dermal and Transdermal Skin Permeation Enhancers
}

\author{
Kristýna Dvořáková ${ }^{1}$, Petr Štěpánek ${ }^{2}$, Jiřina Kroupová ${ }^{3}$ [D and Jarmila Zbytovská ${ }^{1, *}$ \\ 1 Department of Organic Technology, University of Chemistry and Technology Prague, Technická 5, \\ 16628 Prague, Czech Republic; Kristyna1.Dvorakova@vscht.cz \\ 2 Department of Chemistry of Natural Compounds, University of Chemistry and Technology Prague, \\ Technická 5, 16628 Prague, Czech Republic; Petr.Stepanek@vscht.cz \\ 3 Department of Chemical Engineering, University of Chemistry and Technology Prague, Technická 5, \\ 16628 Prague, Czech Republic; Jirina.Kroupova@vscht.cz \\ * Correspondence: Jarmila.Zbytovska@vscht.cz
}

check for updates

Citation: Dvořáková, K.; Štěpánek, P.; Kroupová, J.; Zbytovská, J.

N-Alkylmorpholines: Potent Dermal and Transdermal Skin Permeation

Enhancers. Pharmaceutics 2022, 14, 64 . https://doi.org/10.3390/

pharmaceutics14010064

Academic Editor: Elka Touitou

Received: 2 December 2021

Accepted: 25 December 2021

Published: 28 December 2021

Publisher's Note: MDPI stays neutral with regard to jurisdictional claims in published maps and institutional affiliations.

Copyright: (C) 2021 by the authors. Licensee MDPI, Basel, Switzerland. This article is an open access article distributed under the terms and conditions of the Creative Commons Attribution (CC BY) license (https:// creativecommons.org/licenses/by/ $4.0 /)$.

\begin{abstract}
Transdermal drug delivery is an attractive non-invasive method offering numerous advantages over the conventional routes of administration. The main obstacle to drug transport is, however, the powerful skin barrier that needs to be modulated, for example, by transdermal permeation enhancers. Unfortunately, there are still only a few enhancers showing optimum properties including low toxicity and reversibility of enhancing effects. For this reason, we investigated a series of new $N$-alkylmorpholines with various side chains as potential enhancers in an in vitro permeation study, using three model permeants (theophylline, indomethacin, diclofenac). Moreover, electrical impedance, transepidermal water loss, cellular toxicity and infrared spectroscopy measurements were applied to assess the effect of enhancers on skin integrity, reversibility, toxicity and enhancers' mode of action, respectively. Our results showed a bell-shaped relationship between the enhancing activity and the hydrocarbon chain length of the $N$-alkylmorpholines, with the most efficient derivatives having 10-14 carbons for both transdermal and dermal delivery. These structures were even more potent than the unsaturated oleyl derivative. The best results were obtained for indomethacin, where particularly the C10-14 derivatives showed significantly stronger effects than the traditional enhancer Azone. Further experiments revealed reversibility in the enhancing effect, acceptable toxicity and a mode of action based predominantly on interactions with stratum corneum lipids.
\end{abstract}

Keywords: dermal and transdermal drug delivery; skin permeation enhancers; skin barrier; morpholine derivatives

\section{Introduction}

The transdermal application of drugs is an important administration route, providing many benefits, such as the avoidance of the first-pass metabolism, controlled drug delivery over long time periods, and increased patient compliance. The main aim of the transdermal formulation is an adequate drug permeation rate through the skin to the bloodstream $[1,2]$. On the contrary, in dermal delivery, the major target is the skin tissue where sufficient drug concentrations are needed. However, for both transdermal and dermal deliveries, the skin protective function hinders the entrance of external substances into the organism and therefore represents a fundamental obstacle. The main skin barrier is located in its uppermost layer, the stratum corneum (SC) [3,4]. SC has a special arrangement described as the "brick and mortar model", where the "bricks" represent corneocytes, the terminally differentiated epidermal cells filled with keratin. The "mortar" is the lipid matrix of characteristic composition (ceramides, cholesterol and free fatty acids of various lengths) [5]. This special arrangement ensures the essential barrier function but also limits the diffusive transport of drugs [6-8]. 
One of the methods of overcoming the skin barrier, to increase the penetration of drugs, is the application of skin permeation enhancers [9]. These substances increase the drug flow through the SC, mainly by one or more of the following mechanisms: (i) interactions with SC lipids, (ii) interactions with SC proteins and (iii) increasing the drug solubility in the vehicle and affecting its partitioning in the SC $[10,11]$. Besides a high efficacy, permeation enhancers are required to be non-irritating, non-toxic and non-allergenic. They should not possess their own pharmacological activity, their effect must be reproducible and predictable, and the changes they induce in the skin should be reversible [12,13]. From the regulatory point of view, enhancers are defined as pharmaceutical excipients and should fulfil particular qualitative specifications, including the ability to provide their intended functionality and reversibility of their effect or impact on the adhesive properties of transdermal patches [14,15].

Although many different structures interacting with the SC have been evaluated for their ability to enhance drug permeation via the skin, only a few compounds meet all the qualitative demands. Moreover, most of the enhancers are not universal and are effective for only a limited number of drugs. Therefore, the scale of permeation enhancers should be rather broad to ensure an optimum drug/enhancer combination for each particular formulation. Efficient methods of skin permeation enhancement are essential also from the commercial point of view. Currently, to approve a new transdermal product on the market, it must provide substantial clinical benefits like significantly higher drug bioavailability compared to analogous oral formulations [11]. All of these facts inspire scientists to search for new structures showing high enhancing activity and the other required properties.

Many potent permeation enhancers are amphiphilic - they possess a polar and nonpolar part in their molecule. Such enhancers favourably solubilise the drug and simultaneously penetrate the SC lipid lamellae. Their polar heads interact with the polar regions by breaking the hydrogen-bonding network and their hydrophobic chains incorporate between the chains of SC lipids, causing a disturbance of the rigid lipid packing, lateral fluidisation and a decrease of the skin barrier resistance. Such amphiphilic structure can be found in Azone-, amino acid- and sugar- derivatives, carbamates, terpene derivatives and others $[7,16]$. Amphiphilic enhancers often reveal a bell-shaped relationship between the enhancing activity and their hydrocarbon chain length with maxima at 10-12 carbons for saturated and 18 carbons for unsaturated analogues [11].

An amphiphilic character can also be found in morpholine and thiomorpholine derivatives, which were employed several times as skin permeation enhancers [17-20]. The alkylmorpholine structure can be derived from the established enhancer $N$-lauryl caprolactam (Azone) by substituting the seven-member ring with the hexane one. It was postulated that the dodecyl morpholine derivatives, in particular, can work as highly potent enhancers and that the morpholine structure is worth investigating [21,22].

This study aimed to synthesise new types of morpholine derivatives as potential skin permeation enhancers. Compared to the structures studied earlier, the hydrocarbon chain in our compounds was not linked by an amide bond. Moreover, we extended the polar head by hydroxymethyl substituents, which could increase the capability to form hydrogen bonds. Our synthetic approach was relatively simple including only two steps. The starting materials were glycosides which are readily available and come from renewable sources.

To investigate their enhancing activity in vitro, we prepared a series of various analogues with saturated (C4-C18) and unsaturated (C18) chains and performed a permeation study using three model permeants of different physico-chemical properties: theophylline (TH), indomethacin (IND) and diclofenac (DF). The most potent enhancers were further evaluated for the reversibility of their effect, mode of action and skin toxicity, using transepidermal water loss (TEWL) measurements, Fourier-transform infrared (FT-IR) spectroscopy and a viability assay study on HaCaT cell line, respectively. 


\section{Materials and Methods}

\subsection{Materials for In Vitro Studies}

Permeation enhancers (Table 1) were synthesised in the house (see Supplementary Material). Their partition coefficients $\log P$ were calculated by Chemicalize software (ChemAxon, Budapest, Hungary).

Table 1. The structure of the studied morpholine derivatives and their calculated $\log P$ values, $\mathrm{R}=$ alkyl chain, 18/1 indicates the double bond in position 9 .

\begin{tabular}{cccc}
\hline & Enhancer & \multicolumn{1}{c}{$\mathbf{R}$} & logP \\
\cline { 2 - 4 } & $\mathrm{Mo}$ & $\mathrm{C}_{4} \mathrm{H}_{9}$ & 0.94 \\
& $\mathrm{Mo8}$ & $\mathrm{C}_{8} \mathrm{H}_{17}$ & 2.72 \\
& $\mathrm{Mo10}$ & $\mathrm{C}_{10} \mathrm{H}_{21}$ & 3.61 \\
& $\mathrm{Mo12}$ & $\mathrm{C}_{12} \mathrm{H}_{25}$ & 4.50 \\
& $\mathrm{Mo14}$ & $\mathrm{C}_{14} \mathrm{H}_{29}$ & 5.39 \\
& $\mathrm{Mo18}$ & $\mathrm{C}_{18} \mathrm{H}_{37}$ & 7.17 \\
& $\mathrm{Co18/1}$ & $\mathrm{C}_{18} \mathrm{H}_{35}$ & 6.81 \\
\hline
\end{tabular}

Methanol, acetonitrile, theophylline (TH), diclofenac sodium (DF), indomethacin (IND), gentamicin sulphate and phosphate-buffered saline (PBS) tablets were all purchased from Merck life science (Darmstadt, Germany). Azone-N-dodecylazacykloheptan-2-on was purchased from USBiological (Swampscott, MA, USA). Propylene glycol (PG) was purchased from Dr Kulich Pharma (Hradec Králové, Czech Republic). Acetic acid was purchased from Penta (Praha, Czech Republic). All solvents used were of HPLC grade. Water was deionised, distilled and filtered by a Millipore Q purification system.

PBS solution was prepared by dissolving 1 PBS tablet in deionised water $(200 \mathrm{~mL})$ at $25{ }^{\circ} \mathrm{C}$ to yield a $0.01 \mathrm{M}$ phosphate buffer, $\mathrm{pH} 7.4$.

\subsection{Synthesis of the Morpholine Derivatives}

For general synthetic materials, instrumentation, procedure and characterisation of the prepared compounds, see Supplementary Material.

\subsection{Effect of Enhancers on Drug Solubility}

The effect of enhancers on drug solubility in the donor phase (thermodynamic activity) was determined as follows: $400 \mu \mathrm{L}$ of the prepared donor sample (see Section 2.5.2) were thoroughly mixed and further incubated for $48 \mathrm{~h}$ as in the permeation experiment. Afterwards, the samples were centrifuged for $15 \mathrm{~min}, 2000 \times g$ at $32{ }^{\circ} \mathrm{C}$ (OHaus, Nänikon, Switzerland) and the supernatant was further diluted with the relevant mobile phase for the particular model drug and analysed by HPLC (see Section 2.4).

\subsection{High-Performance Liquid Chromatography (HPLC) Analysis}

Samples were analysed by a Prominence LC-20 reverse-phase high-performance chromatograph (Shimadzu, Kyoto, Japan), equipped with the following: LC-20AD solvent delivery module with DGU-20A degasser; SIL-20AC autosampler; CTO-20AC column oven; SPD-M20A UV /VIS photodiode array detector; CBM-20A communication module. LCsolution software (1.11 SP1) was used to evaluate the data.

\subsubsection{Theophylline}

TH was analysed on CC 250/4.6 LICHROSPHER 100 RP 18, $5 \mu \mathrm{m}$ column (MachereyNagel, Germany) at $30^{\circ} \mathrm{C}$ with methanol: PBS (pH 7.4) in ratio 40: $60(v / v)$ as mobile phase. The flow rate was $1 \mathrm{~mL} \cdot \mathrm{min}^{-1}$, injection volume $20 \mu \mathrm{L}$ and detection wavelength $271 \mathrm{~nm}$. The retention time of TH was $4.2 \pm 0.1 \mathrm{~min}$. The column was equipped with a security guard (Phenomenex, Torrance, CA, USA) with SecurityGuardTM Cartridges (C18 $4 \times 3 \mathrm{~mm}$ ID, Phenomenex, Torrance, CA, USA). The TH limit of detection (LOD) was $0.0005 \mathrm{mg} / \mathrm{mL}$ and the limit of quantification (LOQ) was $0.002 \mathrm{mg} / \mathrm{mL}$. 


\subsubsection{Indomethacin}

IND was analysed on CC 250/4.6 LICHROSPHER 100 RP 18, 5 нm column (MachereyNagel, Germany). The mobile phase consisted of acetonitrile: water: acetic acid 90:60: 5 $(v / v / v)$. The flow rate was $1.5 \mathrm{~mL} \cdot \mathrm{min}^{-1}$, injection volume $40 \mu \mathrm{L}$, column temperature $40{ }^{\circ} \mathrm{C}$ and detection wavelength $260 \mathrm{~nm}$. The retention time of IND was $5.0 \pm 0.1 \mathrm{~min}$. The column was equipped with a security guard (Phenomenex, Torrance, CA, USA) with SecurityGuardTM Cartridges (C18 $4 \times 3 \mathrm{~mm}$ ID, Phenomenex, Torrance, CA, USA). The IND LOD was $0.001 \mathrm{mg} / \mathrm{mL}$ and LOQ was $0.003 \mathrm{mg} / \mathrm{mL}$.

\subsubsection{Diclofenac}

DF was analysed on CC 150/4.6 KINETEX ${ }^{\circledR} 100$ RP 18, 5 m (Phenomenex, Torrance, CA, USA). For the mobile phase, we used methanol: $0.1 \%$ acetic acid in water $(v / v)$ in the ratio of $80: 20(v / v)$. The flow rate was $1 \mathrm{~mL} \cdot \mathrm{min}^{-1}$, column temperature $25^{\circ} \mathrm{C}$, injection volume $20 \mu \mathrm{L}$ and detection wavelength $279 \mathrm{~nm}$. The retention time of DF was $4.0 \pm 0.1 \mathrm{~min}$. The column was equipped with a security guard (Phenomenex, Torrance, CA, USA) with SecurityGuardTM Cartridges (C18 $4 \times 3 \mathrm{~mm}$ ID, Phenomenex, Torrance, CA, USA). The DF LOD was $0.0002 \mathrm{mg} / \mathrm{mL}$ and LOQ was $0.0005 \mathrm{mg} / \mathrm{mL}$. All the HPLC methods were previously validated $[23,24]$.

\subsection{In Vitro Permeation Experiments}

\subsubsection{Skin Preparation}

Porcine earlobes were purchased from a local slaughterhouse. In the first step, hairs were removed by a trimmer. After that, the skin was isolated by a dissector. The thickness of the skin was $1.02 \pm 0.04 \mathrm{~mm}$. The obtained skin sheets were washed in PBS and stored at $-20{ }^{\circ} \mathrm{C}$ for a maximum of 3 months.

\subsubsection{Donor Samples' Preparation}

Three drugs were used as model permeants, namely TH $\left(\mathrm{Mw}=180.16 \mathrm{~g} \cdot \mathrm{mol}^{-1}\right.$, $\log \mathrm{P}=-0.02, \mathrm{pKa}=8.81$; Drugbank, ALOGPS; solubility in PBS $=7.65 \mathrm{mg} \cdot \mathrm{mL}^{-1}$ [25]), IND $\left(\mathrm{Mw}=357.79 \mathrm{~g} \cdot \mathrm{mol}^{-1}, \log \mathrm{P}=4.27, \mathrm{pKa}=4.5 ;\right.$ Drugbank, ALOGPS; solubility in PBS $\left.=0.65 \mathrm{mg} \cdot \mathrm{mL}^{-1}[26]\right)$, and $\mathrm{DF}\left(\mathrm{Mw}=318.13 \mathrm{~g} \cdot \mathrm{mol}^{-1}, \log \mathrm{P}=4.26, \mathrm{pKa}=4.0\right.$; Drugbank, ALOGPS; solubility in PBS $=5.15 \mathrm{mg} \cdot \mathrm{mL}^{-1}$ [27]). The donor samples were prepared as $5 \%(w / v)$ suspension of TH, DF and 2.5\% $(w / v)$ suspension of IND; all in $60 \%$ PG in distilled water $(v / v)$. Some donor samples were used as negative controls. To others, $1 \%$ $(w / v)$ of the particular morpholine derivative was added. In this part of the study, all the synthesised alkylmorpholines (Table 1 ) were tested. Azone $(1 \% w / v$ in $60 \%$ aqueous PG) was used as a positive control. All samples were vortexed several times for $10 \mathrm{~min}$ and stored in an incubator at $32{ }^{\circ} \mathrm{C}$ for $24 \mathrm{~h}$ prior to the permeation experiment. Before application to the skin, the samples were re-suspended by vigorous shaking on the vortex.

\subsubsection{Permeation Experiment}

To study the activity of the permeation enhancers, Franz-type diffusion cells with a diffusion area of $1 \mathrm{~cm}^{2}$ were used. The square fragments of thawed skin were mounted on the diffusion cells, dermal side down and donor and acceptor compartments were clamped together. The acceptor compartment was filled with 5-6 $\mathrm{mL}$ of PBS $(\mathrm{pH}=7.4)$ containing $50 \mathrm{mg} \cdot \mathrm{L}^{-1}$ of gentamicin, to prevent microbial contamination upon sample storage. The PBS was used for its capability to simulate and maintain physiological $\mathrm{pH}$ and isotonicity. The precise volume of each cell was always determined for inclusion in later calculations. The acceptor phase was stirred by a magnetic bar and placed in a water bath thermostated at $32{ }^{\circ} \mathrm{C}$ throughout the experiment. After a hydration equilibrium period of $2-3 \mathrm{~h}$ (PBS in the acceptor compartment, empty donor compartment), the skin integrity was verified by initial TEWL measurements of intact skins, using a Tewameter ${ }^{\circledR}$ TM 300 probe and a Multi Probe Adapter Cutometer ${ }^{\circledR}$ MPA 580 (C+K electronics, Köln, Germany). Thereafter, 500 $\mathrm{mL}$ of PBS was added for $15 \mathrm{~min}$ to estimate the skin electrical impedance (see Section 2.6 
for more detail). In the next step, the PBS was completely removed and $300 \mu \mathrm{L}$ of the donor suspensions, shaken on a vortex immediately prior to use, were applied to the skin surface. The diffusion cells were covered by parafilm to minimise evaporation. During the permeation experiments running for $48 \mathrm{~h}, 300 \mu \mathrm{L}$ of the acceptor phase was withdrawn in defined time intervals and replaced with the same volume of fresh acceptor buffer solution.

\subsubsection{Permeation Evaluation}

The cumulative amount $(Q)$ of the model drugs which permeated across the skin, was corrected for acceptor phase replacement and cell volume and plotted against time. Steady-state flux (Jss) values were calculated as the slope of the linear part of the permeation curves. The potencies of the particular enhancers were expressed as the enhancement ratio $(E R)$ of the permeant flux with and without the enhancer according to

$$
E R=\frac{J_{s s_{\text {enhancer }}}}{J_{S s_{\text {control }}}}
$$

The permeation coefficients $\left(K_{p}\right)$ of the particular permeants in the skin were calculated according to $K_{p}=\frac{I_{S S}}{c_{0}}$, where $\mathrm{c}_{0}$ is the concentration of the permeant in the donor compartment.

\subsubsection{Entrapment of API in the Skin}

At the end of the permeation experiment, the Franz diffusion cells were dismounted and the skin surface was thoroughly washed by distilled water and PBS. The skin area, which was exposed to the donor phase, was cut out, weighed and extracted by $5 \mathrm{~mL}$ of the respective mobile phase by shaking for $24 \mathrm{~h}$ at $32{ }^{\circ} \mathrm{C}$ on a laboratory shaker. The extracts were then filtered through $0.45 \mu \mathrm{m}$ cellulose filters to eliminate skin residues and analysed by HPLC. Drug concentration in the skin, expressed as mg of model drugs per $\mathrm{g}$ of the skin tissue was calculated by dividing permeants' amounts by the respective skin weights.

\subsection{Electrical Impedance Measurements}

For monitoring the skin integrity and characterisation of the permeation enhancers' effect, the electrical impedance of each skin was measured, using an LCR 4080 multimeter (Voltcraft, Hirschau, Germany), set in parallel-equivalent mode with an alternating current frequency of $120 \mathrm{~Hz}$. The measurements were carried out according to established protocols $[25,26,28-31]$. The measurements were performed in the Franz diffusion cells. After the initial hydration and equilibration, the donor compartments were filled with $500 \mu \mathrm{L}$ of PBS. One wire of the multimeter was placed in PBS in the acceptor, the other in the donor phase and the electrical impedance was determined. The next measurement was taken after the $48 \mathrm{~h}$ permeation experiment. When the donor samples $(300 \mathrm{~mL})$ were removed, they were replaced with $500 \mu \mathrm{L}$ PBS and the electrical impedance was re-measured. The electrical impedance ratio (EIR) was calculated for each cell as

$$
E I R=\frac{E I_{1}}{E I_{2}}
$$

where $E I_{1}[\mathrm{k} \Omega]$ is electrical impedance before and $E I_{2}[\mathrm{k} \Omega]$ after the $48 \mathrm{~h}$ treatment by the donor formulation.

\subsection{Transepidermal Water Loss (TEWL) Measurements}

The reversibility of the enhancers' effects was studied by evaluation of the difference in the water loss through the intact and enhancer-treated skin. It was measured using a Tewameter ${ }^{\circledR}$ TM 300 probe and a Multi Probe Adapter Cutometer ${ }^{\circledR}$ MPA 580 (C+K electronics, Köln, Germany). The TEWL measurements were carried out according to established protocols [31-35]. The skin samples were mounted into Franz diffusion cells, with the acceptor compartments filled with PBS pH 7.4 and placed in a water bath at 
$32{ }^{\circ} \mathrm{C}$ to hydrate and equilibrate. At first, the base TEWL values of untreated skin samples were measured. Each of the Franz diffusion cells was removed from the water bath, dried completely with compressed air and inserted into a holder. Then the TEWL probe was placed $1.0 \mathrm{~cm}$ above the skin surface. The measuring time was on average $80-100 \mathrm{~s}$. The steady-state values were noted at comparable ambient conditions (air temperature $24-26{ }^{\circ} \mathrm{C}$ and relative air humidity 27-46\%). After this base TEWL value measurement, $150 \mu \mathrm{L}$ of $1 \%$ of the selected enhancer (Mo10,12, 14 or Azone) in $60 \%$ aqueous PG or of the control (60\% aqueous PG with no enhancer) was applied into the donor compartment. The cells were then incubated at $32{ }^{\circ} \mathrm{C}$. The donor samples were removed after $2 \mathrm{~h}$ or $24 \mathrm{~h}$ and the skin surface was washed with $0.5 \mathrm{~mL}$ of PBS, gently blotted dry and thoroughly dried with compressed air. After the enhancer was removed, TEWL was measured at predetermined intervals over 42 or $50 \mathrm{~h}$.

\subsection{Attenuated Total Reflectance (ATR)-FTIR Measurements}

ATR-FTIR is a powerful method to investigate the interactions of enhancers with SC lipids and proteins. The skin was mounted to Franz diffusion cells in a water bath at $32{ }^{\circ} \mathrm{C}$ and treated with $180 \mu \mathrm{L}$ of $1 \%$ enhancers (Mo10, Mo12, Mo14, Mo18/1) in $60 \%$ aqueous PG. Pure distilled water or $60 \%$ aqueous PG were applied as controls. After $24 \mathrm{~h}$ exposure, the donor phase was carefully removed, the skin was washed by distilled water and the exposed skin was cut out. IR spectra of the skin surface were recorded by an IR spectrometer (Nicolet iZ10, Thermo Scientific, Waltham, MA, USA), equipped with a single reflection MIRacle ZnSe crystal (PIKE Technologies, Madison, WI, USA) at constant clamping pressure. The spectra were generated by the co-addition of 64 scans, collected at a resolution of $2 \mathrm{~cm}^{-1}$ and evaluated by OMNIC ${ }^{\mathrm{TM}}$ software (Thermo Scientific, Waltham, MA, USA). Collected spectra were normalised, to reduce potential variations in the overall intensity of the spectra. Selected regions (amide I, amide II and $\mathrm{CH}_{2}$ stretching vibration bands) were fitted in Origin Pro (OriginLab, Wellesley Hills, MA, USA). The position, height and area of these selected peaks were compared among the particular spectra and the variances between peak characteristics were statistically evaluated by GraphPad Prism ${ }^{\circledR}$ software (GraphPad Software, Inc., La Jolla, CA, USA).

\subsection{Toxicity Measurements}

Cytotoxicity of the three best enhancers (Mo10, Mo12, Mo14) was evaluated on nonmalignant spontaneously immortalised human keratinocytes HaCaT (Cell Lines Service, Eppelheim, Germany). The cell line was cultivated in Dulbecco's Modified Eagle's Medium (DMEM, Sigma Aldrich, St. Luis, MO, USA), supplemented with 10\% Fetal Bovine Serum (Sigma Aldrich, St. Luis, MO, USA) in a Petri dish at $37{ }^{\circ} \mathrm{C}$ in a humidified atmosphere of $5 \% \mathrm{CO}_{2}$. Cells were subcultured two times a week. For cytotoxicity experiments, 96-well plates were seeded with cells (at a density of 10,000 cells per well) in $100 \mu \mathrm{L}$ of culture medium and incubated at $37{ }^{\circ} \mathrm{C}$ in a humidified atmosphere of $5 \% \mathrm{CO}_{2}$ for $24 \mathrm{~h}$.

The enhancers were dissolved in DMEM, left in an ultrasonic bath for $15 \mathrm{~min}$ and then kept at $37^{\circ} \mathrm{C}$ overnight. On the next day, $10 \mu \mathrm{L}$ of the particular enhancer solution was added to $100 \mu \mathrm{L}$ of cell suspensions, to receive final enhancer concentrations in the range of 0.9-110 $\mu \mathrm{M}$ (concentrations determined according to our preliminary testing). The cells were incubated with tested compounds for $24 \mathrm{~h}$. Then, the cell viability was determined, using the Cell Counting Kit-8 (CCK-8, Sigma Aldrich, St. Luis, MO, USA). The cells were incubated with $10 \mu \mathrm{L}$ of the CCK-8 for $2 \mathrm{~h}$. Thereafter, absorbance was measured at $450 \mathrm{~nm}$, using the Infinite 200 PRO microplate reader (Tecan Austria GmbH, Austria). The mean optical density (absorbance) was used to calculate the percentage of cell viability as follows:

$$
\text { percentage of cell viability }=\frac{A_{\text {treatment }}-A_{\text {blank }}}{A_{\text {control }}-A_{\text {blank }}} \times 100 \%,
$$

where $A$ is the absorbance. The viability assay was expressed as the concentration of enhancers causing $50 \%$ cells' inhibition $\left(\mathrm{IC}_{50}\right)$. 


\subsection{Statistical Analysis}

Statistical analysis was performed with the GraphPad Prism statistical program (La Jolla, CA, USA). The outlier values were eliminated using Grubbs's test. This test is suitable for a large dataset with a normally distributed population. A one-way ANOVA with Dunnetts' post-test and t-test were used. The differences were considered significant at $p<0.05$. Data are presented as means \pm SEM (standard error of the mean).

\section{Results and Discussion}

\subsection{The Morpholine Derivatives Show Significant Enhancing Effects}

In this work, we studied seven new morpholine derivatives with various side-chain lengths as potential skin permeation enhancers. The saturated chain lengths were of 4-18 carbons. In addition, an unsaturated derivative with an oleyl chain was included. The effect of the enhancers was investigated on porcine skin, using three model drugs. TH was selected as a relatively small molecule with balanced hydrophilic/lipophilic properties and solubility in the donor phase of $20.02 \pm 0.62 \mathrm{mg} \cdot \mathrm{mL}^{-1}$. The other model permeants, IND and $\mathrm{DF}$, were larger molecules with higher lipophilicity than that of $\mathrm{TH}$, but they differed in their solubility in the donor phase. IND was only slightly soluble $\left(0.95 \pm 0.51 \mathrm{mg} \cdot \mathrm{mL}^{-1}\right)$ compared to the well soluble DF $\left(57.77 \pm 2.55 \mathrm{mg} \cdot \mathrm{mL}^{-1}\right)$. Because of the different physicochemical properties, the selected compounds are proposed to penetrate the SC by different mechanisms. While small hydrophilic molecules are likely to cross the skin barrier by free volume diffusion, the larger lipophilic compounds prefer a lateral diffusion along lipid bilayers $[26,36,37]$. According to our previous experience, $60 \%$ PG in water was used as the vehicle for the donor samples. Cosolvents like PG or ethanol often act synergistically with amphiphilic permeation enhancers [38]. It was shown that aqueous PG changes the conformation of SC proteins, but does not interact with SC lipids, which are mainly the target of amphiphilic enhancers [26,29]. We aimed to utilise this synergy and support the possible effects of our compounds.

The results of the permeation study are presented in Table 2. Examples of the permeation profiles of the drugs combined with the most potent compounds are shown in Figure 1a-c. The control TH sample without an enhancer resulted in TH flux of $3.04 \pm 0.51 \mu \mathrm{g} \cdot \mathrm{cm}^{-2} \cdot \mathrm{h}^{-1}$. The IND and DF flux values from the pure vehicle were $0.51 \pm 0.09 \mu \mathrm{g} \cdot \mathrm{cm}^{-2} \cdot \mathrm{h}^{-1}$ and $5.74 \pm 1.04 \mu \mathrm{g} \cdot \mathrm{cm}^{-2} \cdot \mathrm{h}^{-1}$, respectively. Our studies showed that all the morpholine derivatives were efficient as permeation enhancers and able to significantly increase the flux of all three drugs. The most enhancing potency was shown by the morpholine derivatives possessing 10-14 carbons in their side chain. This corresponds to the previously reported data for various structures, stating that chains of middle lengths are the most efficient in enhancement $[16,39]$. The strongest permeation- enhancing effect for $\mathrm{TH}$ and IND was found for Mo12 $\left(\mathrm{ER}_{\mathrm{Mo12}, \mathrm{TH}}=14.53\right.$ and $\left.\mathrm{ER}_{\mathrm{Mo12,IND}}=10.01\right)$. The most potent enhancer for DF was Mo14 $\left(\mathrm{ER}_{\mathrm{Mo14}, \mathrm{DF}}=2.58\right)$. Compared to the positive control Azone (ER 15.34, 1.95 and 4.23, for TH, IND and DF, respectively), the morpholine derivatives show favourable results. Concerning IND, Mo12 has even significantly higher effects than Azone. 
Table 2. Effects of the studied enhancers (1\%) on the permeation of the model drugs applied at $2.5 \%$ $w / v$ (IND) and $5 \% w / v$ (TH, DF) in $60 \%$ PG with or without the enhancer. Solubility of model drugs in the donor samples $\left(c_{o}\right)$, steady-state flux values $\left(J_{s s}\right)$, enhancement ratio (ER), permeability coefficient $\left(K_{\mathrm{p}}\right)$, the concentration of model drugs in the skin ( $\left.\mathrm{c}_{\text {skin }}\right)$. Data are presented as the means $\pm \mathrm{SEM}$, $n \geq 16$. ${ }^{*}$ Statistically significant difference compared to the negative control (without enhancers) at $p<0.05 .{ }^{\dagger}$ Statistically significant increase compared to a positive control (with Azone) at $p<0.05$.

\begin{tabular}{|c|c|c|c|c|c|}
\hline TH & $\begin{array}{c}\mathrm{c}_{\mathrm{o}} \\
\left(\mathrm{mg} \cdot \mathrm{mL}^{-1}\right)\end{array}$ & $\begin{array}{c}\mathrm{Jss}_{\mathrm{ss}} \\
\left(\mu \mathrm{g} \cdot \mathrm{cm}^{-2} \cdot \mathrm{h}^{-1}\right)\end{array}$ & ER & $\begin{array}{c}\mathrm{K}_{\mathrm{p}} \times 10^{-4} \\
\left(\mathrm{~cm} \cdot \mathrm{h}^{-1}\right)\end{array}$ & $c_{\text {skin }}\left(\mu \mathrm{g} \cdot \mathrm{mg}^{-1}\right)$ \\
\hline Control & $20.02 \pm 0.62$ & $3.04 \pm 0.51$ & - & 1.52 & $214.70 \pm 32.20$ \\
\hline Mo4 & $21.36 \pm 3.42$ & $4.19 \pm 0.56$ & 1.38 & 1.96 & $343.40 \pm 84.88$ * \\
\hline Mo8 & $21.19 \pm 4.56$ & $14.11 \pm 2.15$ & 4.63 & 6.66 & $626.30 \pm 21.71 *$ \\
\hline Mo10 & $21.19 \pm 1.40$ & $30.05 \pm 6.78$ * & 9.87 & 14.18 & $814.33 \pm 53.07^{*}$ \\
\hline Mo12 & $20.83 \pm 3.30$ & $44.25 \pm 5.95$ * & 14.53 & 21.24 & $1277.71 \pm 133.41$ * \\
\hline Mo14 & $20.20 \pm 2.73$ & $26.40 \pm 2.47 *$ & 8.67 & 13.07 & $104.73 \pm 88.95^{*}$ \\
\hline Mo18 & $20.87 \pm 2.18$ & $9.32 \pm 1.49$ & 3.06 & 4.46 & $645.39 \pm 44.11 *$ \\
\hline Mo18/1 & $20.67 \pm 3.84$ & $15.27 \pm 1.22$ * & 5.01 & 7.39 & $685.17 \pm 85.83 *$ \\
\hline Azone & $23.96 \pm 2.76$ & $46.71 \pm 4.22^{*}$ & 15.34 & 19.50 & $1435.43 \pm 85.83$ * \\
\hline IND & $\begin{array}{c}\mathrm{c}_{\mathrm{o}} \\
\left(\mathrm{mg} \cdot \mathrm{mL}^{-1}\right)\end{array}$ & $\underset{\left(\mu \mathrm{g} \cdot \mathrm{cm}^{-2} \cdot \mathrm{h}^{-1}\right)}{\mathrm{Js}}$ & ER & $\begin{array}{l}\mathrm{K}_{\mathrm{p}} \times 10^{-4} \\
\left(\mathrm{~cm} \cdot \mathrm{h}^{-1}\right)\end{array}$ & $c_{\text {skin }}\left(\mu g \cdot \mathrm{mg}^{-1}\right)$ \\
\hline Control & $0.95 \pm 0.51$ & $0.51 \pm 0.09$ & - & 3.75 & $32.43 \pm 6.98$ \\
\hline Mo4 & $4.18 \pm 0.41$ & $2.94 \pm 0.48^{* \dagger}$ & 5.78 & 7.02 & $146.34 \pm 34.40 *$ \\
\hline Mo8 & $5.21 \pm 0.29 * \dagger$ & $3.19 \pm 0.56^{* \dagger}$ & 6.28 & 6.13 & $222.14 \pm 47.68$ * \\
\hline Mo10 & $5.94 \pm 0.42 * \dagger$ & $3.97 \pm 0.55^{* \dagger}$ & 7.80 & 6.67 & $398.07 \pm 93.01 *$ \\
\hline Mo12 & $4.90 \pm 0.94 * \dagger$ & $5.09 \pm 0.66^{*+}$ & 10.01 & 10.39 & $563.20 \pm 102.73 * t$ \\
\hline Mo14 & $4.03 \pm 1.04$ & $4.62 \pm 0.622^{* \dagger}$ & 9.10 & 11.49 & $182.36 \pm 34.26^{*}$ \\
\hline Mo18 & $2.86 \pm 1.70$ & $0.99 \pm 0.15$ & 1.95 & 3.47 & $79.23 \pm 21.00 *$ \\
\hline Mo18/1 & $2.10 \pm 0.85$ & $2.00 \pm 0.29$ & 3.94 & 9.55 & $158.99 \pm 42.45 *$ \\
\hline Azone & $1.03 \pm 0.77$ & $0.99 \pm 0.12$ & 1.95 & 9.60 & $197.14 \pm 45.54$ * \\
\hline DF & $\begin{array}{c}\mathrm{c}_{\mathrm{o}} \\
\left(\mathrm{mg} \cdot \mathrm{mL}^{-1}\right)\end{array}$ & $\frac{J_{s s}}{\left(\mu \mathrm{g} \cdot \mathrm{cm}^{-2} \cdot \mathrm{h}^{-1}\right)}$ & ER & $\begin{array}{c}\mathrm{K}_{\mathrm{p}} \times 10^{-4} \\
\left(\mathrm{~cm} \cdot \mathrm{h}^{-1}\right)\end{array}$ & $c_{\text {skin }}\left(\mu g \cdot \mathrm{mg}^{-1}\right)$ \\
\hline Control & $57.77 \pm 2.55$ & $5.74 \pm 1.04$ & - & 0.99 & $380.10 \pm 50.52$ \\
\hline Mo4 & $51.13 \pm 1.33$ & $5.94 \pm 0.55$ & 1.04 & 1.16 & $417.01 \pm 56.55$ * \\
\hline Mo8 & $57.88 \pm 8.75$ & $6.73 \pm 0.99$ & 1.17 & 1.16 & $449.36 \pm 43.55 *$ \\
\hline Mo10 & $50.76 \pm 3.08$ & $8.21 \pm 1.39 *$ & 1.43 & 1.62 & $651.06 \pm 78.35^{*}$ \\
\hline Mo12 & $57.30 \pm 9.62$ & $10.37 \pm 1.62$ * & 1.81 & 1.81 & $777.36 \pm 106.27 *$ \\
\hline Mo14 & $60.79 \pm 6.02$ & $14.82 \pm 2.78$ * & 2.58 & 2.44 & $717.53 \pm 153.49 *$ \\
\hline Mo18 & $50.12 \pm 6.00$ & $6.57 \pm 0.68$ & 1.14 & 1.31 & $499.29 \pm 61.12 *$ \\
\hline Mo18/1 & $54.03 \pm 7.78$ & $11.16 \pm 1.74$ * & 1.94 & 2.06 & $744.89 \pm 138.39 *$ \\
\hline Azone & $57.00 \pm 5.02$ & $24.25 \pm 2.47$ * & 4.23 & 4.25 & $1916.98 \pm 307.15 *$ \\
\hline
\end{tabular}

The introduction of a double bond into the side chain in Mo18/1 increased its enhancing potency, compared to the saturated derivative Mo18, for all model permeants. This effect was rather expected and was also reported in the literature [13]. The cis-double bond creates a kink in the carbonyl chain that is, therefore, able to interact more efficiently with skin lipids. It is assumed that the oleyl group supports a phase separation and disruption of the otherwise ordered array of saturated straight bands of the lipids [40-42]. Interestingly, the unsaturated derivative was overall not the most potent one. Especially in the case of TH and IND, the shorter chain length saturated derivatives Mo10-14 showed a significantly stronger enhancing effect. 
a)

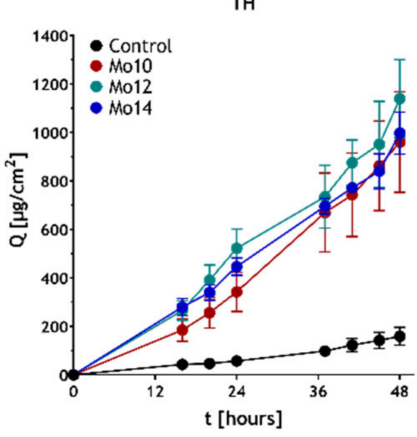

d)

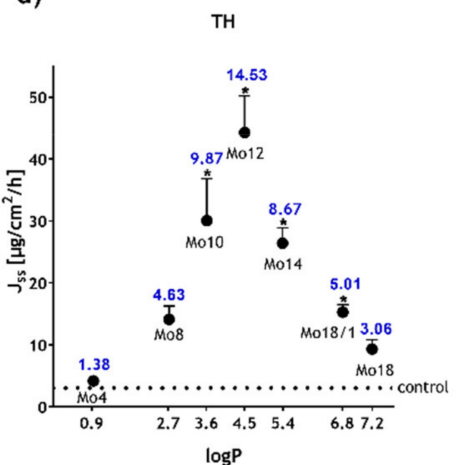

b)

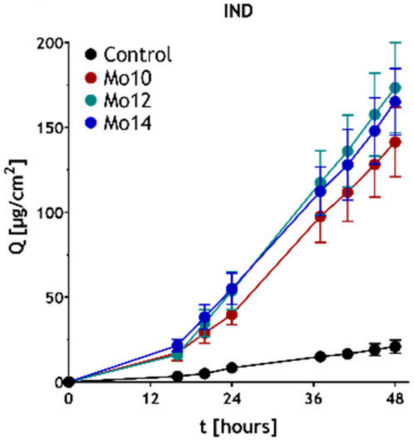

e)

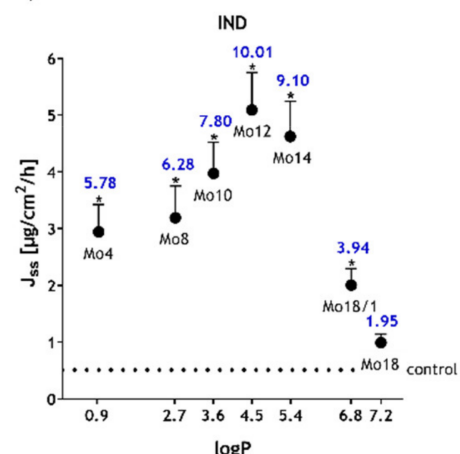

c)

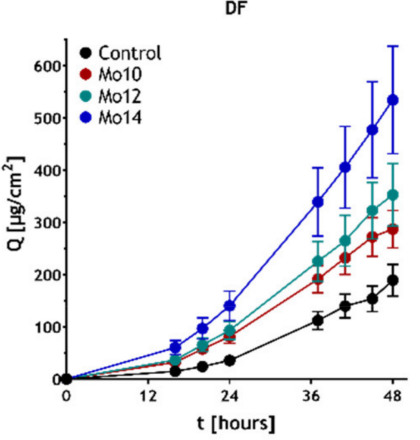

f)

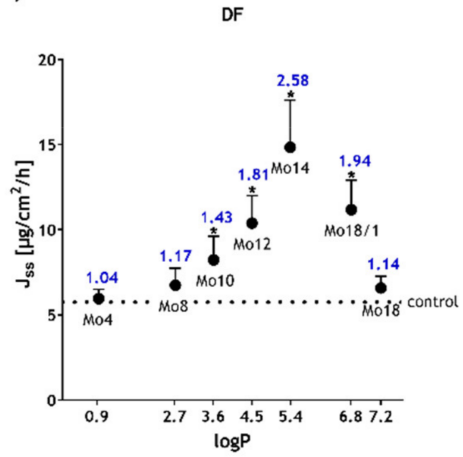

Figure 1. Effects of the studied enhancers (1\%) on skin permeability. Permeation profiles of TH (a), IND (b) and DF (c) for the most active enhancers. Flux of TH (d), IND (e) and DF (f) vs. LogP of the studied enhancers. The black dotted line represents the flux of model drugs from a pure vehicle (with no enhancer). The blue numbers represent enhancing ratios. Data are presented as means $\pm \mathrm{SEM}, n \geq 16 ;{ }^{*}$ Statistically significant differences compared to the negative control (pure vehicle) at $p<0.05$.

In general, our results showed a bell-shaped dependency between the side-chain length in the morpholine structure and the enhancing activity for all the permeants. Similar effects were described previously for Azone derivatives, amino acids, lactate, ceramides derivatives and others $[43,44]$. It was suggested that shorter chain analogues would provide a more permeable shortcut for penetrating compounds, probably due to the formation of free space within the SC lipid lamellae, which would then be filled by neighbouring chains, causing lateral fluidisation of the tightly packed lamellar arrangement [45]. Naturally, the length of the side chain influences the overall lipophilicity of the molecule. An interesting relationship is therefore shown in Figure $1 \mathrm{~d}-\mathrm{f}$, where the calculated $\log \mathrm{P}$ values of the enhancers are related to their enhancing effects. The values of the unsaturated derivative Mo18/1 also fit well into this correlation. These results hint at the importance of lipophilicity of the permeation enhancers; more specifically, at their partition abilities between a hydrophilic and lipophilic phase and, by extension, between a vehicle and the SC lipid matrix as suggested earlier [45].

Considering the solubility of the permeants in the donor phase $\left(\mathrm{c}_{0}\right.$ in Table 2$)$, the $\mathrm{TH}$ and DF values were hardly affected by the presence of any morpholine derivative. However, the addition of enhancers increased the solubilities of otherwise sparingly soluble IND, showing a bell-like dependency, approximately correlating with the flux results. This indicates a solubilisation ability of our compounds in particular for less soluble lipophilic drugs. This could contribute to the final enhancing effect and explain why the IND permeation is more enhanced $\left(E R_{M o 12, I N D}=10.01\right)$ than that of $D F\left(E R_{M o 14, D F}=2.58\right)$. In any case, this increase in solubility has probably only a minor effect on the overall enhancing activity. The permeation coefficients $\left(\mathrm{K}_{\mathrm{p}}\right)$, describing the ability of the permeants 
to diffuse inside the membrane, were significantly influenced by the enhancers for all the model drugs, corresponding to the bell-like relationships of their flux values. This indicates that the enhancers directly interacted with the skin barrier.

\subsection{The Morpholine Derivatives Increase the Amount of Drugs Accumulated in the Skin}

After the permeation experiment, the amount of the model permeants in the skin tissue was determined in relation to the used permeation enhancer $\left(c_{\text {skin }}\right.$ in Table 2$)$. For all the permeants, the studied enhancers significantly increased the accumulation in the skin compared to the negative control. The highest amount of entrapped drugs were found for enhancement by the middle-chained morpholines (Mo10-Mo14) and also for that containing the oleyl moiety (Mo18/1). The absolutely best dermal targeting effect was reached by Mo12 (for TH $1277.71 \pm 133.41$ compared to control $214.7 \pm 32.20 \mu \mathrm{g}$ per $\mathrm{g}$ of the skin $\left(\mu \mathrm{g} \cdot \mathrm{g}_{\text {skin }}{ }^{-1}\right)$; for IND $563.20 \pm 102.73$ compared to control $32.43 \pm 6.98 \mu \mathrm{g} \cdot \mathrm{g}_{\text {skin }}{ }^{-1}$ and for DF $777.36 \pm 106.27$ compared to $380.10 \pm 50.52 \mu \mathrm{g} \cdot \mathrm{g}_{\text {skin }}{ }^{-1}$ ). Especially in the case of TH and IND, Mo12 showed comparable or even significantly stronger effects than the positive control Azone. Even though the targeting of DF was the most intensive with the use of Mo12, Mo14 was also able to ensure a high amount of the drug in the skin layers $\left(717.53 \pm 153.49 \mu \mathrm{g} \cdot \mathrm{g}_{\text {skin }}{ }^{-1}\right.$ compared to $380.10 \pm 50.52 \mu \mathrm{g} \cdot \mathrm{g}_{\text {skin }}{ }^{-1}$ of the control). These results indicate that the studied enhancers may show their potential not only in transdermal but also in dermal drug delivery. This is an important finding because the formation of a dermal depot is one way to achieve a constant and intensive influx of a drug into the bloodstream [46].

\subsection{The Morpholine Derivatives Reduce Skin Barrier Function}

Electrical impedance (EI) provides important information about the skin barrier integrity and permeability. Therefore, it can be used to characterise direct interactions between enhancers and the skin barrier. In general, higher impedance values mean that the skin barrier is more resistant to the permeation of small charged molecules (e.g., ions) [28,47]. It was shown that EI decreased after the application of permeation enhancers or water $[26,34,47]$. Figure 2 shows the ratios of the skin electrical impedance (EIR), calculated from the EI measured before and after the enhancers' application. The use of this ratio provides a clearer means of expressing the enhancers' influence, without it being hindered by the diversity of the particular skin samples and long hydration times [26,48]. The ratio values for the intact skin control (IND, DF, TH in $60 \%$ PG) were set to 1, to emphasise the individual effect of the enhancers according to previous studies [48].

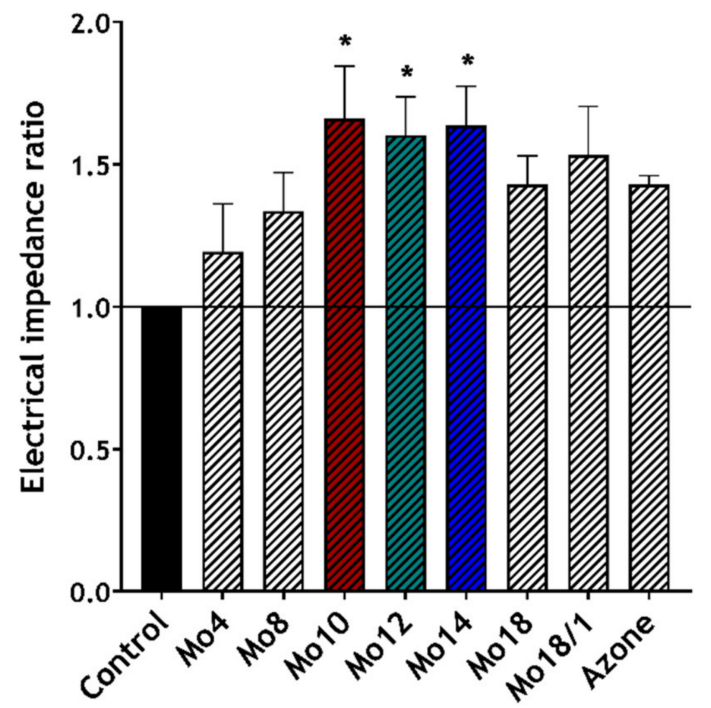

Figure 2. Effects of the studied enhancers (1\%) on the skin electrical impedance ratio (EIR). Mean \pm SEM, $n \geq 12$; ${ }^{*}$ Statistically significant difference compared to the negative control. 
The main increase in the impedance ratio was achieved by the Mo10, 12 and 14 derivatives. Their EIR values of $1.66 \pm 0.19 ; 1.60 \pm 0.13 ; 1.64 \pm 0.14$, respectively, were significantly higher than that of the untreated controls (impedance ratio value set to 1) and also higher than Azone. These results confirmed that our compounds can interact directly with the skin barrier and reduce its function. Moreover, we also found a slight bell-shaped trend concerning the side chain length, which correlates with our other findings about the enhancers' effects.

\subsection{The Morpholine Derivatives Interact with Skin Lipids}

IR spectroscopy was applied to study the interactions of the most efficient derivatives (Mo10, Mo12, Mo14) or Azone with the skin barrier, at the molecular level. Moreover, Mo18/1 was also characterised because, contrary to the other derivatives, it possessed the unsaturated side chain which could lead to different interactions. We focused primarily on the region of $\mathrm{CH}_{2}$ symmetric $\left(v_{\mathrm{s}} \mathrm{CH}_{2}\right)$ and asymmetric $\left(v_{\mathrm{as}} \mathrm{CH}_{2}\right)$ stretching vibrations at around 2850 and $2918 \mathrm{~cm}^{-1}$, respectively. These bands are related to the arrangement of the lipids in the SC. Low positions of these bands (up to $2850 \mathrm{~cm}^{-1}$ for $v_{\mathrm{S}} \mathrm{CH}_{2}$ ) indicate higher proportions of trans-conformations and rigidity of the hydrocarbon chains in a crystalline lipid phase. Higher positions of these modes are related to loosening of the rigid arrangement and increased membrane fluidity [49,50]. Table 3 presents the positions of all the studied modes. The skin treated with the pure vehicle (aqueous PG without enhancers) showed $v_{\mathrm{s}} \mathrm{CH}_{2}$ and $v_{\mathrm{as}} \mathrm{CH}_{2}$ at $2850.72 \pm 0.19$ and $2919.36 \pm 0.33 \mathrm{~cm}^{-1}$, respectively. These positions correlated with previously published results [48,51,52] and indicated relatively well-ordered lipid chains, with predominant trans-conformations in the SC matrix. Shifts of $\mathrm{CH}_{2}$-stretching vibrations to higher positions by $1-2 \mathrm{~cm}^{-1}$ were observed after the skin exposure to the enhancers. This indicated an increasing proportion of gauche- conformers in the SC lipid chains, which corresponded to a decrease in their order and increasing fluidity. The most significant shifts were observed in skin treated with Mo10 and Mo12. Azone and the unsaturated derivative Mo18/1 also caused an increase in the $v_{\mathrm{s}} \mathrm{CH}_{2}$ compared to the negative control, though this effect was slighter.

Table 3. Positions of the symmetric and asymmetric $\mathrm{CH} 2$ - stretching vibrations $\left(v_{\mathrm{s}} \mathrm{CH} 2\right.$ and $v_{\mathrm{as}} \mathrm{CH} 2$, respectively) for the skins treated with selected enhancers measured by ATR-FTIR. Data are presented as means \pm SEM, $n \geq 9$. ${ }^{*}$ Statistically significant difference compared to the respective control (pure vehicle) at $p<0.05$.

\begin{tabular}{ccc}
\hline & $\boldsymbol{v}_{\mathbf{s}} \mathbf{C H}_{\mathbf{2}}$ & $\boldsymbol{v}_{\text {as }} \mathbf{C H}_{\mathbf{2}}$ \\
\hline Control & $2850.72 \pm 0.19$ & $2919.36 \pm 0.33$ \\
Mo10 & $2852.58 \pm 0.71^{*}$ & $2921.91 \pm 0.40$ \\
Mo12 & $2851.56 \pm 0.23^{*}$ & $2921.14 \pm 0.61$ \\
Mo14 & $2850.74 \pm 0.14$ & $2919.48 \pm 0.42$ \\
Mo 18/1 & $2850.76 \pm 0.15$ & $2920.35 \pm 0.36$ \\
Azone & $2851.16 \pm 0.21^{*}$ & $2921.84 \pm 0.34$ \\
\hline
\end{tabular}

The positions and shapes of the peaks of amide II $\left(1546 \mathrm{~cm}^{-1}\right)$ and amide I $\left(1638 \mathrm{~cm}^{-1}\right)$ vibrations, which characterise the protein components of the SC, particularly keratin, were also examined. None of the studied enhancers induced significant shifts of the amide modes compared to the control.

Our findings suggest that the main mode of action of the studied enhancers may lay in their interactions with skin lipids. The enhancers increased the fluidity of the SC lipid chains which was documented by the increase in the $\mathrm{v}_{\mathrm{s}} \mathrm{CH}_{2}$ and $\mathrm{v}_{\mathrm{as}} \mathrm{CH}_{2}$ positions. In particular, the saturated derivatives of decyl- and dodecyl- chains (Mo10 and 12) showed significant changes in the IR-spectra. On the contrary, no changes in the amide region of the SC spectrum indicate that the enhancers do not affect the protein (particularly keratin) conformation in the SC. The observed effects are similar to those described previously for various amphiphilic enhancers [25,34,53]. 


\subsection{Effects of the Morpholine Derivatives on the Skin Barrier Are Reversible}

One of the current requirements on permeation enhancers is the reversibility of their effects. This means that the skin barrier can recover its function after the enhancer is removed or has ended its action. To monitor this effect, transepidermal water loss (TEWL) measurements were applied. This method has earlier been confirmed as a suitable tool to detect the reversibility of enhancers' action in vitro [34,53]. Figure 3 shows the development of TEWL after the enhancers or control acting for 2 or $24 \mathrm{~h}$ were removed. The values before the application ranged from 3.1 to $5.8 \mathrm{~g} \cdot \mathrm{m}^{-2} \cdot \mathrm{h}^{-1}$. These values were consistent with other studies [54]. After the $2 \mathrm{~h}$-treatment by Mo10, Mo12 and Mo14 the TEWL values increased to $11.7 \pm 0.8 \mathrm{~g} \cdot \mathrm{m}^{-2} \cdot \mathrm{h}^{-1}, 8.2 \pm 0.3 \mathrm{~g} \cdot \mathrm{m}^{-2} \cdot \mathrm{h}^{-1}$ and $9.0 \pm 0.4 \mathrm{~g} \cdot \mathrm{m}^{-2} \cdot \mathrm{h}^{-1}$, respectively. This increase was significant compared to the respective baseline values. For comparison, the control sample (60\% aqueous PG) at the same time point also showed an increase in TEWL but not significantly different. Later, further to the enhancers' removal, all the TEWL values slowly decreased to close to the original levels. After $20 \mathrm{~h}$, the difference in TEWL between the treated and control samples was not significant anymore. The values of $4.8 \pm 0.1 \mathrm{~g} \cdot \mathrm{m}^{-2} \cdot \mathrm{h}^{-1}, 3.2 \pm 0.3 \mathrm{~g} \cdot \mathrm{m}^{-2} \cdot \mathrm{h}^{-1}$ and $4.6 \pm 0.7 \mathrm{~g} \cdot \mathrm{m}^{-2} \cdot \mathrm{h}^{-1}$ for Mo10, Mo12 and Mo14, respectively, were in the same range as $4.4 \pm 0.8 \mathrm{~g} \cdot \mathrm{m}^{-2} \cdot \mathrm{h}^{-1}$ for the control. Therefore, the effect after a short-term $2 \mathrm{~h}$ application of Mo10, 12 and 14 was found to be reversible.

a)

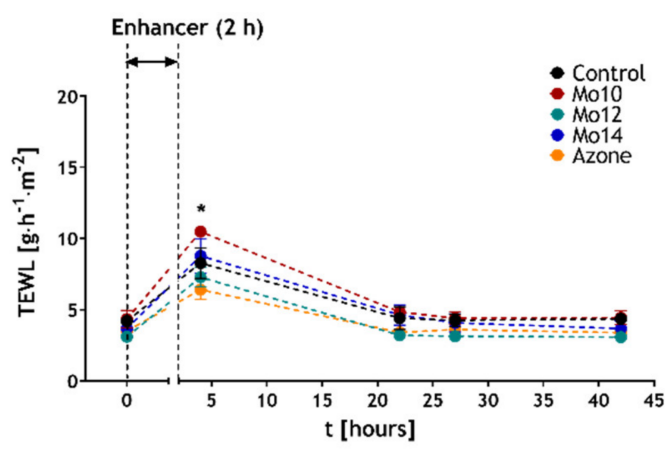

b)

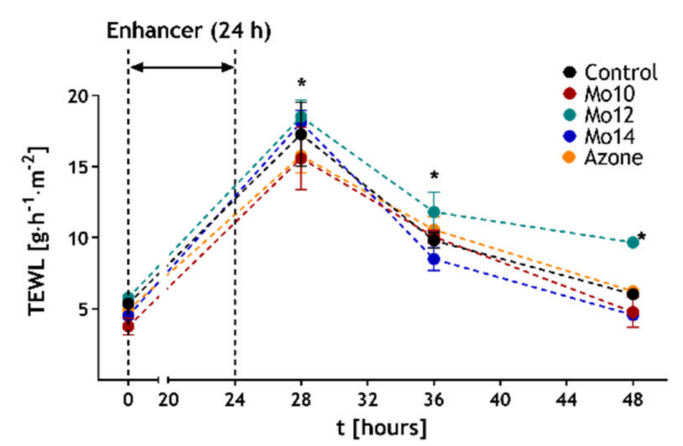

Figure 3. The reversibility of enhancers- effects on skin TEWL when applied for $2 \mathrm{~h}$ (a) and $48 \mathrm{~h}$ (b). Mean \pm SEM, $n \geq 5$; ${ }^{*}$ Statistically significant difference compared to the respective control (pure vehicle).

To study the reversibility process after a longer application on the skin barrier, we prolonged the enhancer exposure period to $24 \mathrm{~h}$. After this treatment, the TEWL significantly increased compared to the baseline to $15.6 \pm 2.2 \mathrm{~g} \cdot \mathrm{m}^{-2} \cdot \mathrm{h}^{-1}, 18.5 \pm 1.2 \mathrm{~g} \cdot \mathrm{m}^{-2} \cdot \mathrm{h}^{-1}$ and $18.1 \pm 0.8 \mathrm{~g} \cdot \mathrm{m}^{-2} \cdot \mathrm{h}^{-1}$ for Mo 10,12 and 14, respectively. Within the following $24 \mathrm{~h}$ after the enhancers' removal, the TEWL of the skin treated with enhancers dropped to values of $4.3 \pm 0.7 \mathrm{~g} \cdot \mathrm{m}^{-2} \cdot \mathrm{h}^{-1}, 9.5 \pm 0.1 \mathrm{~g} \cdot \mathrm{m}^{-2} \cdot \mathrm{h}^{-1}$ and $4.7 \pm 0.1 \mathrm{~g} \cdot \mathrm{m}^{-2} \cdot \mathrm{h}^{-1}$, respectively. This did not significantly differ from the control or baseline values before the treatment for Mo10 and Mo14. The TEWL of the skin exposed to Mo12 decreased as well, but more slowly and, even at the end of the experiment, the values were still significantly higher compared to the baseline. The long-term exposure experiment confirmed the reversibility of the enhancers' effects on the skin barrier, particularly for the Mo10 and Mo14 derivatives. The longer regenerative time for $\mathrm{Mo} 12$ can be related to its intensive enhancing function, causing more notable changes in the SC arrangement. Nevertheless, the skin barrier regeneration might be supported by the addition of a renewing agent into the final formulation [48].

To compare our compounds with traditional enhancers, we also treated the skin with Azone according to the same experimental protocol. The development of the TEWL values in time was analogous to the trends of the studied enhancers (Figure 3), confirming the relevance of our derivatives as enhancers with a reversible function. 


\subsection{Cytotoxicity Assay of the Most Efficient Enhancers}

The cellular toxicity of the most efficient enhancers (Mo10, Mo12 and Mo14) was studied on the spontaneously immortalised human keratinocytes (HaCaT) cell line. To determine the concentration of the tested enhancers, which cause a $50 \%$ decrease in cell viability $\left(\mathrm{IC}_{50}\right), \mathrm{CCK}-8$ was utilised. Figure 4 shows the cell viability in relation to the concentration of the particular enhancers. The $\mathrm{IC}_{50}$ of Mo12 and Mo14 was determined at $41.0 \pm 0.8 \mu \mathrm{M}$ and $41.5 \pm 1.5 \mu \mathrm{M}$, respectively. Interestingly, for Mo10 the value $94.0 \pm 1.5 \mu \mathrm{M}$ was almost double the previous ones. This is consistent with previous studies describing increasing skin toxicity with increasing chain length by various amphiphilic structures $[55,56]$. The $\mathrm{IC}_{50}$ values of our compounds were comparable to or even safer than several enhancers described earlier, e.g., Azone ( $49 \mu \mathrm{M}$ [57], $116.9 \mu \mathrm{M}$ [58]), proline derivative L-Pro2 $(68 \mu \mathrm{M})$ [29,34], DDAK $(76 \mu \mathrm{M})$, Transkarbam $12(21 \mu \mathrm{M})$ [29] or dodecyl amino glucoside $(24 \mu \mathrm{M})$ [34]. This indicates that our compounds show acceptable toxicity and the further potential of application in topical drug delivery.

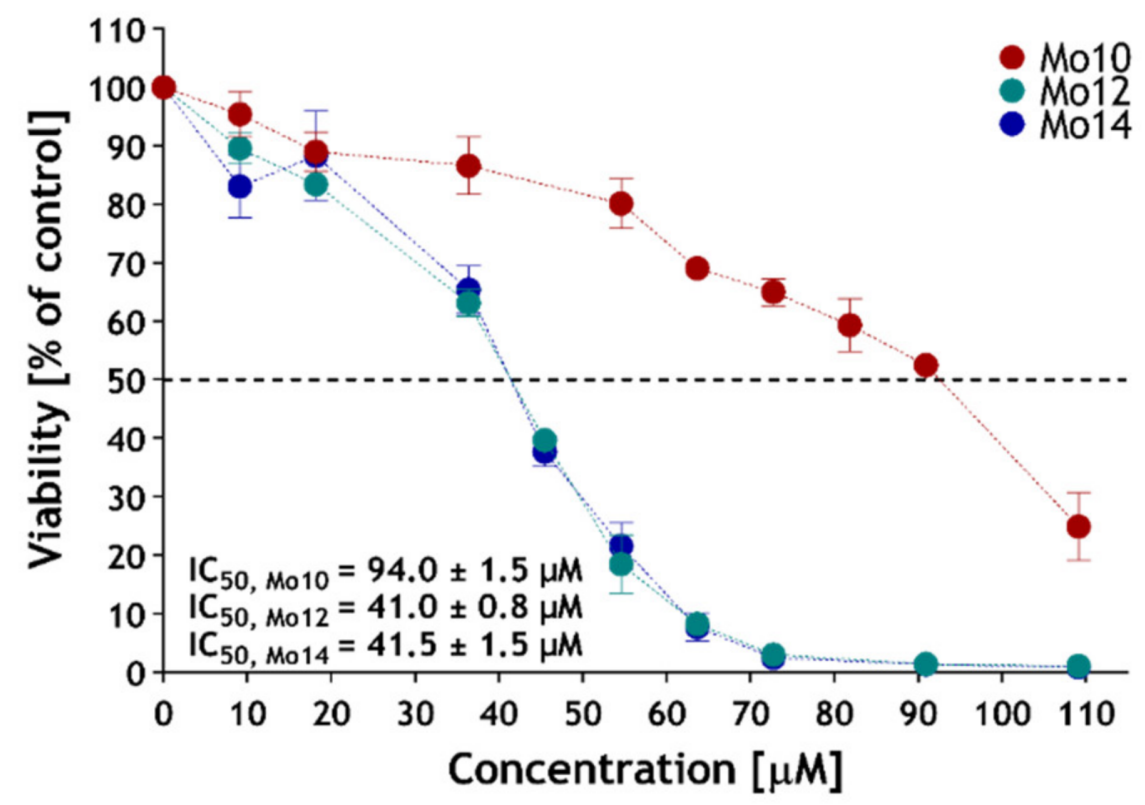

Figure 4. The viability of human keratinocyte cell lines (HaCaT) after $24 \mathrm{~h}$ incubation with selected permeation enhancers (Mo10, Mo12, Mo14). Data are presented as means $\pm \mathrm{SEM}, n \geq 4$.

\section{Conclusions}

In this study, we synthesised novel $N$-alkylmorpholines with various chain lengths and evaluated their activity as skin permeation enhancers. In vitro skin permeation experiments with three different model permeants revealed the high enhancing potency of the prepared compounds. The most efficient morpholine derivatives were those possessing 10-14 chain lengths in both transdermal and dermal delivery. For permeants with higher lipophilicity and low solubility, represented by IND in our study, the $\mathrm{N}$-alkylmorpholines showed significantly stronger effects than the established enhancer Azone. The enhancing effect may be supported by the $N$-alkymorpholines' ability to solubilise IND. Comparable or weaker enhancing effects than those of Azone were achieved for substances with higher solubility (TH, DF) where no solubilisation was observed.

In the subsequent experiments, we focused on the mode of action and safety of the most active enhancers. Using EI and FTIR-spectroscopy, we showed that the main mode of action is probably based on interactions with skin barrier lipids. The fluidity of their hydrocarbon chains increased and the lipids lost their rigid arrangement under the enhancers' influence. These effects were, however, temporary as confirmed by TEWL. Moreover, the cytotoxicity assay revealed $\mathrm{IC}_{50}$ values comparable to other established 
enhancers. $N$-alkylmorpholines have been shown as promising skin permeation enhancers for local or systemic treatment, meeting the current safety requirements.

Though the potential clinical application of the studied $N$-alkylmorpholines is still disputable, they show benefits that qualify them for further investigation. Their simple synthesis based on available natural sources enables additional functionalisation by other substituents which can be used to further optimise the enhancing effects. In future research, we plan to focus on the structural modifications, optimisation of enhancers formulation, their concentration and, possibly, in vivo studies.

Supplementary Materials: The following are available online at https:/ /www.mdpi.com/article/10 .3390/pharmaceutics14010064/s1; Figure S1: Synthesis of the enhancers; Supporting experimental procedures: Synthesis of the $N$-alkylmorpholines; Characterisation of the prepared compounds.

Author Contributions: Conceptualisation, K.D., P.Š. and J.Z.; methodology, K.D., P.Š. and J.Z.; chemical synthesis, P.Š.; experiments, K.D. and J.K.; data evaluation K.D., J.K. and J.Z.; writingoriginal draft preparation, K.D., P.Š. and J.Z.; writing-review and editing, K.D. and J.Z.; supervision, J.Z.; project administration, J.Z. All authors have read and agreed to the published version of the manuscript.

Funding: This research was funded by the Czech Science Foundation, grant number GACR19-09600S. KD was funded by Specific University Research (MSMT No. A2_FCHT_2021_081).

Institutional Review Board Statement: Not applicable.

Informed Consent Statement: Not applicable.

Data Availability Statement: Data are contained within the article.

Acknowledgments: This study was financially supported by the Czech Science Foundation (GACR1909600S). K.D. thanks Specific University Research (MSMT No. A2_FCHT_2021_081) for financial support. We would like to thank Radek Stibor for providing the porcine skin and Aneta Vovesná and Pearl Harris for language editing of the manuscript.

Conflicts of Interest: The authors declare no conflict of interest. The funders had no role in the design of the study; the collection, analyses, or interpretation of data; in the writing of the manuscript, or in the decision to publish the results.

\section{References}

1. Ashok, K.; Nikhila, P.; Lakshmana, P.; Gopal, V. Transdermal Drug Delivery System: An Overview. Int. J. Pharm. Sci. Rev. Res. 2010, 3, 49-54.

2. Sharadha, M.; Gowda, D.V.; Vishal Gupta, N.; Akhila, A.R. An Overview on Topical Drug Delivery System-Updated Review. Int. J. Res. Pharm. Sci. 2020, 11, 368-385. [CrossRef]

3. Menon, G.K.; Norlén, L. Stratum Corneum Ceramides and Their Role in Skin Barrier Function. In Skin Moisturization; CRC Press: Boca Raton, FL, USA, 2002; pp. 55-84.

4. Prausnitz, M.R.; Langer, R. Transdermal Drug Delivery. Nat. Biotechnol. 2008, 26, 1261-1268. [CrossRef]

5. Harding, C.R. The Stratum Corneum: Structure and Function in Health and Disease. Dermatol. Ther. 2004, 17, 6-15. [CrossRef] [PubMed]

6. Barry, B.W. Novel Mechanisms and Devices to Enable Successful Transdermal Drug Delivery. Eur. J. Pharm. Sci. 2001, 14, 101-114. [CrossRef]

7. Moser, K.; Kriwet, K.; Naik, A.; Kalia, Y.N.; Guy, R.H. Passive Skin Penetration Enhancement and Its Quantification in vitro. Eur. J. Pharm. Biopharm. 2001, 52, 103-112. [CrossRef]

8. Menon, G.K.; Cleary, G.W.; Lane, M.E. The Structure and Function of the Stratum Corneum. Int. J. Pharm. 2012, 435, 3-9. [CrossRef] [PubMed]

9. Chantasart, D.; Li, S.K. Structure Enhancement Relationship of Chemical Penetration Enhancers in Drug Transport across the Stratum Corneum. Pharmaceutics 2012, 4, 71-92. [CrossRef] [PubMed]

10. Barry, B.W. Lipid-Protein-Partitioning Theory of Skin Penetration Enhancement. J. Control. Release 1991, 15, 237-248. [CrossRef]

11. Kováčik, A.; Kopečná, M.; Vávrová, K. Permeation Enhancers in Transdermal Drug Delivery: Benefits and Limitations. Expert Opin. Drug Deliv. 2020, 17, 145-155. [CrossRef]

12. Williams, A.C.; Barry, B.W. Penetration Enhancers. Adv. Drug Deliv. Rev. 2004, 56, 603-618. [CrossRef]

13. Lane, M.E. Skin Penetration Enhancers. Int. J. Pharm. 2013, 447, 12-21. [CrossRef] 
14. European Medicines Agency. Guidline on Quality of Transdermal Patches; EMA/CHMP/QWP/608924/2014; Committee for Medicinal Products for Human Use: London, UK, 2014.

15. Food and Drug Administration. Guidance for Industry, Transdermal and Topical Delivery Systems-Product Development and Quality Considerations; FDA-2019-D-4447; Center for Drug Evaluation and Research (CDER): Silver Spring, MD, USA, 2019.

16. Vávrová, K.; Zbytovská, J.; Hrabálek, A. Amphiphilic Transdermal Permeation Enhancers: Structure-Activity Relationships. Curr. Med. Chem. 2005, 12, 2273-2291. [CrossRef] [PubMed]

17. Phillips, C.A.; Michniak, B.B. Transdermal Delivery of Drugs with Differing Lipophilicities Using Azone Analogs as Penetration Enhancers. Proc. Control. Release Soc. 1995, 84, 648-649. [CrossRef]

18. Michniak, B.B.; Player, M.R.; Godwin, D.A.; Phillips, C.A.; Sowell, J.W. In Vitro Evaluation of a Series of Azone Analogs as Dermal Penetration Enhancers: IV. Amines. Int. J. Pharm. 1995, 116, 201-209. [CrossRef]

19. Michniak, B.B.; Player, M.R.; Fuhrman, L.C.; Christensen, C.A.; Chapman, J.M.; Sowell, J.W. In Vitro Evaluation of a Series of Azone Analogs as Dermal Penetration Enhancers: III. Acyclic Amides. Int. J. Pharm. 1994, 110, 231-239. [CrossRef]

20. Michniak, B.B.; Player, M.R.; Chapman, J.M.; Sowell, J.W. Azone Analogues as Penetration Enhancers: Effect of Different Vehicles on Hydrocortisone Acetate Skin Permeation and Retention. J. Control. Release 1994, 32, 147-154. [CrossRef]

21. Dragicevic, N.; Atkinson, J.P.; Maibach, H.I. Chemical penetration enhancers: Classification and mode of action. In Percutaneous Penetration Enhancers Chemical Methods in Penetration Enhancement; Springer: Berlin/Heidelberg, Germany, 2015 ; pp. 78-107.

22. Jampílek, J.; Brychtová, K. Azone Analogues: Classifcation, Design, and Transdermal Penetration Principles. Med. Res. Rev. 2012, 32, 907-947. [CrossRef]

23. Novotný, M.; Hrabálek, A.; Janůšová, B.; Novotný, J.; Vávrová, K. Dicarboxylic Acid Esters as Transdermal Permeation Enhancers: Effects of Chain Number and Geometric Isomers. Bioorganic Med. Chem. Lett. 2009, 19, 344-347. [CrossRef]

24. Školová, B.; Kováčik, A.; Tesař, O.; Opálka, L.; Vávrová, K. Phytosphingosine, Sphingosine and Dihydrosphingosine Ceramides in Model Skin Lipid Membranes: Permeability and Biophysics. Biochim. Biophys. Acta-Biomembr. 2017, 1859, 824-834. [CrossRef]

25. Kopečná, M.; Macháček, M.; Prchalová, E.; Štěpánek, P.; Drašar, P.; Kotora, M.; Vávrová, K. Galactosyl Pentadecene Reversibly Enhances Transdermal and Topical Drug Delivery. Pharm. Res. 2017, 34, 2097-2108. [CrossRef] [PubMed]

26. Čuř́íková, B.A.; Procházková, K.; Filková, B.; Diblíková, P.; Svoboda, J.; Kováčik, A.; Vávrová, K.; Zbytovská, J. Simplified Stratum Corneum Model Membranes for Studying the Effects of Permeation Enhancers. Int. J. Pharm. 2017, 534, 287-296. [CrossRef] [PubMed]

27. Kincl, S.; Meleh, M.; Veber, M.; Vrecer, F. Study of Physicochemical Parameters Affecting the Release of Diclofenac Sodium from Lipophilic Matrix Tablets. Acta Chim. Slov. 2004, 51, 409-425.

28. Fasano, W.J.; Hinderliter, P.M. The Tinsley LCR Databridge Model 6401 and Electrical Impedance Measurements to Evaluate Skin Integrity In Vitro. Toxicol. Vitro 2004, 18, 725-729. [CrossRef]

29. Janůšová, B.; Školová, B.; Tükörová, K.; Wojnarová, L.; Šimůnek, T.; Přemysl, M.; Filipský, T.; Michal, Ř.; Roh, J.; Palát, K.; et al. Amino Acid Derivatives as Transdermal Permeation Enhancers. J. Control. Release 2013, 165, 91-100. [CrossRef]

30. Karande, P.; Jain, A.; Mitragotri, S. Relationships Between Skin's Electrical Impedance and Permeability in the Presence of Chemical Enhancers. J. Control Release 2006, 110, 307-313. [CrossRef]

31. Zhang, Q.; Murawsky, M.; LaCount, T.; Kasting, G.B.; Li, S.K. Transepidermal Water Loss and Skin Conductance as Barrier Integrity Tests. Toxicol. Vitro 2018, 51, 129-135. [CrossRef]

32. Elkeeb, R.; Hui, X.; Chan, H.; Tian, L.; Maibach, H.I. Correlation of Transepidermal Water Loss with Skin Barrier Properties in vitro: Comparison of Three Evaporimeters. Skin Res Technol. 2010, 16, 9-15. [CrossRef]

33. Netzlaff, F.; Kostka, K.H.; Lehr, C.M.; Schaefer, F.U. TEWL Measurements As a Routine Method for Evaluating the Integrity of Epidermis Sheets in Static Franz Type Diffusion Cells In Vitro. Limitations Shown by Transport Data Testing. Eur. J. Pharm. Biopharm. 2006, 63, 44-50. [CrossRef]

34. Kopečná, M.; Macháček, M.; Prchalová, E.; Štěpánek, P.; Drašar, P.; Kotora, M.; Vávrová, K. Dodecyl Amino Glucoside Enhances Transdermal and Topical Drug Delivery via Reversible Interaction with Skin Barrier Lipids. Pharm. Res. 2017, 34, 640-653. [CrossRef]

35. Nangia, A.; Patil, S.; Berner, B.; Boman, A.; Maibach, H. In vitro Measurement of Transepidermal Water Loss: Rapid Alternative to Tritiated Water Permeation for Assessing Skin Barrier Functions. Int. J. Pharm. 1998, 170, 33-40. [CrossRef]

36. Školová, B.; Janůšová, B.; Zbytovská, J.; Gooris, G.; Bouwstra, J.; Slepička, P.; Berka, P.; Roh, J.; Palát, K.; Hrabálek, A.; et al. Ceramides in the Skin Lipid Membranes: Length Matters. Langmuir 2013, 29, 15624-15633. [CrossRef]

37. Mitragotri, S. Modeling Skin Permeability to Hydrophilic and Hydrophobic Solutes Based on Four Permeation Pathways. J. Control. Release 2003, 86, 69-92. [CrossRef]

38. Karande, P.; Mitragotri, S. Enhancement of Transdermal Drug Delivery via Synergistic Action of Chemicals. Biochim Biophys Acta Biomembr. 2009, 1788, 2362-2373. [CrossRef] [PubMed]

39. Kanikkannan, N.; Kandimalla, K.; Lamba, S.; Singh, M. Structure-Activity Relationship of Chemical Penetration Enhancers in Transdermal Drug Delivery. Curr. Med. Chem. 2012, 7, 593-608. [CrossRef] [PubMed]

40. Green, P.G.; Guy, R.H.; Hadgraft, J. In vitro and in vivo Enhancement of Skin Permeation with Oleic and Lauric Acids. Int. J. Pharm. 1988, 48, 103-111. [CrossRef] 
41. Zbytovská, J.; Vávrová, K.; Kiselev, M.A.; Lessieur, P.; Wartewig, S.; Neubert, R.H.H. The Effects of Transdermal Permeation Enhancers on Thermotropic Phase Behaviour of a Stratum Corneum Lipid Model. Colloids Surf. A Physicochem. Eng. Asp. 2009, 351, 30-37. [CrossRef]

42. Naik, A.; Pechtold, L.A.R.M.; Potts, R.O.; Guy, R.H. Mechanism of Oleic Acid-Induced Skin Penetration Enhancement in Vivo in Humans. J. Control. Release 1995, 37, 299-306. [CrossRef]

43. Vávrová, K.; Hrabálek, A.; Doležal, P.; Šámalová, L.; Palát, K.; Zbytovská, J.; Holas, T.; Klimentová, J. Synthetic Ceramide Analogues as Skin Permeation Enhancers: Structure-Activity Relationships. Bioorg. Med. Chem. Lett. 2003, 11, 5381-5390. [CrossRef] [PubMed]

44. Vávrová, K.; Hrabálek, A.; Doležal, P.; Holas, T.; Zbytovská, J. L-Serine and Glycine Based Ceramide Analogues as Transdermal Permeation Enhancers: Polar Head Size and Hydrogen Bonding. Bioorganic Med. Chem. Lett. 2003, 13, 2351-2353. [CrossRef]

45. Chen, Y.; Quan, P.; Liu, X.; Wang, M.; Fang, L. Novel Chemical Permeation Enhancers for Transdermal Drug Delivery. Asian J. Pharm. Sci. 2014, 9, 51-64. [CrossRef]

46. Khandavilli, S.; Panchagnula, R. Dermal Drug Delivery: Revisited. Drug Discov. Ther. 2008, 2, 64-73. [PubMed]

47. Karande, P.; Jain, A.; Mitragotri, S. Discovery of Transdermal Penetration Enhancers by High-Throughput Screening. Nat. Biotechnol. 2004, 22, 192-197. [CrossRef]

48. Vovesná, A.; Zhigunov, A.; Balouch, M.; Zbytovská, J. Ceramide Liposomes for Skin Barrier Recovery: A Novel Formulation Based on Natural Skin Lipids. Int. J. Pharm. 2021, 596, 120264. [CrossRef] [PubMed]

49. Moore, D.J.; Rerek, M.E.; Mendelsohn, R. FTIR Spectroscopy Studies of the Conformational Order and Phase Behavior of Ceramides. J. Phys. Chem. B 1997, 101, 8933-8940. [CrossRef]

50. Holas, T.; Zbytovská, J.; Vávrová, K.; Berka, P.; Mádlová, M.; Klimentová, J.; Hrabálek, A. Thermotropic Phase Behavior of Long-chain Alkylammonium-alkylcarbamates. Thermochim. Acta 2006, 441, 116-123. [CrossRef]

51. Kong, R.; Bhargava, R. Characterization of Porcine Skin as a Model for Human Skin Studies Using Infrared Spectroscopic Imaging. Analyst 2011, 136, 2359-2366. [CrossRef] [PubMed]

52. Bhatia, K.S.; Gao, S.; Singh, J. Effect of Penetration Enhancers and Iontophoresis on the FT-IR Spectroscopy and LHRH Permeability through Porcine Skin. J. Control. Release 1997, 47, 81-89. [CrossRef]

53. Kopečná, M.; Macháček, M.; Nováčková, A.; Paraskevopoulos, G.; Roh, J.; Vávrová, K. Esters of Terpene Alcohols as Highly Potent, Reversible, and Low Toxic Skin Penetration Enhancers. Sci. Rep. 2019, 9, 14617. [CrossRef]

54. Jacques-Jamin, C.; Jeanjean-Miquel, C.; Domergue, A.; Bessou-Touya, S.; Duplan, H. Standardization of an in Vitro Model for Evaluating the Bioavailability of Topically Applied Compounds on Damaged Skin: Application to Sunscreen Analysis. Skin Pharmacol. Physiol. 2017, 30, 55-65. [CrossRef] [PubMed]

55. Zhang, Y.; Li, X.; Yu, H. Toxicity of Nanoparticle Surface Coating Ag-ents: Structure-Cytotoxicity Relationship. J. Environ. Sci. Health. C Environ. Carcinog. Ecotoxicol. Rev. 2016, 34, 204-215. [CrossRef] [PubMed]

56. Ponec, M.; Haverkort, M.; Lan Soei, Y.; Kempenaar, J.; Brussee, J.; Bodde, H. Toxicity Screening of N-Alkylazacycloheptan-2-on Derivatives in Cultured Human Skin Cells: Structure-Toxicity Relationships. J. Pharm. Sci. 1989, 78, 738-741. [CrossRef] [PubMed]

57. Jiang, Q.; Wu, Y.; Zhang, H.; Liu, P.; Yao, J.; Yao, P.; Chen, J.; Duan, J. Development of Essential Oils as Skin Permeation Enhancers: Penetration Enhancement Effect and Mechanism of Action. Pharm. Biol. 2017, 55, 1592-1600. [CrossRef] [PubMed]

58. Yi, Q.F.; Yan, J.; Tang, S.Y.; Huang, H.; Kang, L.Y. Effect of Borneol on the Transdermal Permeation of Drugs with Differing Lipophilicity and Molecular Organization of Stratum Corneum Lipids. Drug Dev. Ind. Pharm. 2016, 42, 1086-1093. [CrossRef] [PubMed] 